\title{
Prolegómenos para un enfoque de paces cotidianas*
}

\author{
[Versión en Castellano] \\ Prolegomena to an Everyday Peace Approach
}

Prolegômenos para uma abordagem da paz cotidiana

Recibido el 25 de julio de 2020. Aceptado el 27 agosto de 2020.

\author{
Alejandro Granados-García** \\ https://orcid.org/0000-0001-7201-4872
}

Colombia

\section{- Para citar este artículo: \\ Granados-García, Alejandro (2021). Prolegómenos para un enfoque de paces cotidianas. Ánfora, 28(50). 17-44. https://doi.org/10.30854/anf.v28.n50.2021.715 Universidad Autónoma de Manizales. ISSN 0121-6538. E-ISSN 2248-6941. CC BY-NC-SA 4.0}

\section{Resumen}

Objetivo: este trabajo de reflexión busca contribuir a la fundamentación de un enfoque de construcción de paz que apueste a la escala de lo local-cotidiano (del mundo de la vida), sin dejar de lado la interacción y mutua influencia que pueda existir con otras escalas de lo regional, lo nacional y lo transnacional o global. Metodología: el trabajo se estructura a partir de un conjunto de premisas que abren senderos y escenarios de reflexión; se trata de una perspectiva para el trabajo en el campo teórico-práctico de los conflictos y las paces.

\footnotetext{
* Las reflexiones aquí expuestas se nutrieron de las conversaciones al interior del Seminario de línea "Conflictos sociales y armados. Abordajes psicosociales hacia la construcción de culturas de paz" del Doctorado en Psicología de la Pontificia Universidad Javeriana, Sede Bogotá. Quiero dar reconocimiento y agradecer al equipo del Seminario por ofrecer un escenario de encuentro sumamente fértil para la reflexión sobre los conflictos y las paces en Colombia. Quiero agradecer también el trabajo de lectura crítica de quienes evaluaron y revisaron este artículo; sus atinados comentarios contribuyeron a enriquecer significativamente las reflexiones que aquí presento. El autor declara que no hubo conflicto de intereses en la ejecución del proyecto de investigación. Por su carácter reflexivo y a petición del autor, este artículo incluye la voz en primera persona.

** Psicólogo. Politólogo. Magister en Filosofía. Estudiante del Doctorado en Psicología de la Pontificia Universidad Javeriana, Bogotá, Colombia. Correo electrónico: alejogranadosgarcia@gmail.com
} 
Resultados: se identificó la necesidad de pensar críticamente el campo teórico-práctico de los conflictos y las paces desde una perspectiva transdisciplinar y multiescalar de los fenómenos, las actuaciones y las relaciones de poder. También resulta ineludible una perspectiva que evidencie los procesos de colonización de este campo teóricopráctico por parte de los modelos de una paz (neo)liberal y que, a su vez, logre trascender el esquema crítico polarizante del Norte y el Sur. Es importante reivindicar la escala de lo cotidiano, pues ofrece experiencias, prácticas, recursos, perspectivas e interpretaciones relevantes para la comprensión y la transformación de los conflictos y las paces. Conclusiones: se requiere problematizar las paces en las cotidianidades para abordar sus tensiones, contradicciones, dilemas y problemáticas. Con ello, se pretende estimular la comprensión y la conversación en torno a las condiciones de posibilidad de un enfoque para la comprensión y el fortalecimiento de las paces cotidianas.

Palabras-clave: Paz cotidiana; Construcción de paces; Investigación sobre la paz; Conflictividades sociales; Análisis de conflictos; Transdisciplinariedad.

\section{Abstract}

Objective: this article is a reflection seeking to contribute to the foundation of a peace-building approach that focuses on the scale of the local-everyday (of the world of life), without neglecting the interaction and mutual influence that may exist with other scales of the regional, national and transnational or global. Methodology: this article is structured based on a set of premises that open paths and scenarios for reflection; it is a perspective to work in the theoretical-practical field of conflicts and peace. Results: the need to think critically about the theoretical-practical field of conflicts and peace from a transdisciplinary and multiscale perspective of phenomena, actions and power relations was identified. A perspective that evidences the colonization processes of this theoretical-practical field by the models of a (neo) liberal peace is also unavoidable and that, in turn, manages to transcend the critical polarizing scheme of the North and the South. It is important to vindicate the scale of everyday life, as it offers experiences, practices, resources, perspectives and relevant interpretations for the understanding and transformation of conflicts and peace. Conclusions: it is required to problematize peace in everyday life to address its tensions, contradictions, dilemmas and problems. This is intended to stimulate understanding and conversation around the conditions of possibility of an approach to understanding and strengthening everyday peace.

Keywords: Everyday peace; Peace building; Research on peace; Social conflicts; Conflict analysis; Transdisciplinarity. 


\section{Resumo}

Objetivo: este trabalho de reflexão busca contribuir para a fundação de uma abordagem de construção da paz que se concentra na escala do cotidiano local (do mundo da vida), sem parar à parte a interação e influência mútua que pode existir com outras escalas do regional, nacional e transnacional ou global. Metodologia: o trabalho está estruturado a partir de um conjunto de premissas que abrem caminhos e cenários de reflexão; É uma perspectiva de trabalho no campo teórico-prático dos conflitos e da paz. Resultados: identificou-se a necessidade de pensar criticamente o campo teóricoprático dos conflitos e da paz a partir de uma perspectiva transdisciplinar e multiescala dos fenômenos, ações e relações de poder. É também incontornável uma perspectiva que evidencie os processos de colonização desse campo teórico-prático pelos modelos de uma paz (neo) liberal e que, por sua vez, consiga transcender o esquema crítico de polarização do Norte e do Sul. É importante reivindicar a escala do cotidiano, pois oferece experiências, práticas, recursos, perspectivas e interpretações relevantes para a compreensão e transformação dos conflitos e da paz. Conclusões: é necessário problematizar a paz na vida cotidiana para enfrentar suas tensões, contradições, dilemas e problemas. Com isso, pretende-se estimular a compreensão e o diálogo sobre as condições de possibilidade de uma abordagem para a compreensão e fortalecimento da paz cotidiana.

Palavras-chave: Paz diária; Construção da paz; Pesquisa sobre a paz; Conflitos sociais; Análise de conflito; Transdisciplinaridade. 


\section{Introducción}

Existen iniciativas y procesos de paz que emergen, se despliegan y luchan por consolidarse e incidir en las conflictividades presentes en su contexto singular, más allá y más acá de la paz que se administra en los ámbitos de la macropolítica, entre las élites de los distintos bandos en pugna y bajo la tutela de burocracias multinacionales que pretenden gestionar los conflictos en el marco de un paradigma de gobernanza global de las transiciones hacia sociedades y Estados "correctamente" inmersos en el sistema de mercado neoliberal (Castillejo, 2017).

En este artículo presento algunas reflexiones generales con las que aspiro a contribuir a la fundamentación de un enfoque de construcción de paz que apuesta por la escala de lo local-cotidiano (del mundo de la vida), sin dejar de lado las interacciones y mutuas influencias que puedan existir con otras escalas de lo regional, lo nacional y lo transnacional o global. Se trata de una perspectiva para el trabajo en el campo teórico-práctico de los conflictos y las paces. Ahora bien, no solo propongo la reivindicación de la escala de lo cotidiano, sino su problematización. Es por esto que la forma en que está escrito este artículo no pretende exponer una teoría completa y acabada, sino recoger y reflejar un proceso de pensamiento en devenir, a la manera de la metáfora viva de Paul Ricoeur (2001), es decir, un ejercicio de reflexión en gerundio que trae tensiones, contradicciones, desplazamientos, transiciones, dilemas y problemáticas ligadas al significado y las implicaciones del asunto tratado. En pocas palabras, se trata de un texto experimental.

Agradezco de antemano el bondadoso y creativo trabajo de lectura, apropiación, reformulación y crítica que cada lector pueda llevar a cabo a medida que recorre estas páginas. Aspiro a que las reflexiones que presento estimulen ejercicios de lectura y análisis de casos. Así, al final, este trabajo pretende establecer diálogos reflexivos con algunos de los elementos conceptuales que configuran discursos sobre la construcción de paz.

Por otra parte, reconozco el contexto, las lógicas y las dinámicas imperantes en el mundo de la publicación académica. Es por esto que considero importante hacer una acotación sobre mi apuesta por la escritura en primera persona. Quienes producimos y consumimos artículos y otro tipo de materiales académicos sabemos que, por lo general, estos artefactos rehúyen o reniegan del uso de la primera persona como recurso expositivo. El uso del impersonal, que me hace pensar en el das Man del que habla Heidegger, parece ser el dispositivo preferido para evitar cualquier riesgo de contaminación por parte de las informalidades del lenguaje, los sesgos subjetivos, la falta de objetividad y de rigor en la comunicación científica. En este sentido, la redacción impersonal tiende a asociarse con la objetividad y la claridad expositiva que se espera de una producción científica. 
Observo en estas consideraciones que la presencia o ausencia de la voz personal y la predilección por la escritura impersonal rebasa las cuestiones estilísticas y tiene implicaciones epistemológicas. Conlleva implícitamente posturas sobre qué es, cómo se construye, cómo se valida y cómo se comunica el conocimiento científico, así como cuál es el lugar de la subjetividad y la intersubjetividad en ello.

Quiero entonces hacer explícita la posición epistemológica desde la cual considero que la escritura en primera persona puede devenir en una práctica y una apuesta ético-política. La apuesta central desde la cual parto es por reconocer que el conocimiento, como lo advierte la epistemología feminista, es un conocimiento situado (Haraway, 1991). La idea de un saber situado problematiza la presunción de neutralidad y objetividad en la investigación e invita a reconocer el lugar desde donde se investiga, el rol de la mirada parcial en la producción de conocimiento, así como los condicionamientos, contextos, valores, creencias, relacionalidades e interseccionalidades presentes en dicha producción de conocimiento. De acuerdo con Donna Haraway (1991), el saber situado es un conocimiento cuya objetividad no resulta de la pretendida neutralidad sino, más bien, de ejercicios autorreflexivos de los sujetos cognoscentes, examinados con la misma rigurosidad con que se analizan los sujetos conocidos. La objetividad deviene una objetividad parcial. El conocimiento se reconoce embebido por el contex to desde donde se conoce, por las subjetividades implicadas en las relaciones de investigación, por cómo se enuncia y por los presupuestos ontológicos y axiológicos que lo orientan. Bajo esta epistemología, se pone en primer plano la subjetividad y la intersubjetividad que artificialmente desaparecían tras la pretensión de objetividad y el recurso del impersonal.

En definitiva, considero que apostar por el uso de la primera persona en la escritura académica resulta consecuente con el posicionamiento epistemológico y ético-político que asumo a partir de la idea del conocimiento situado. Escribir en primera persona representa, para mí, una invitación a posicionarme como sujeto, a asumir mis propios condicionamientos, limitaciones y posibilidades, así como la responsabilidad por lo que escribo. También es una invitación a generar un escenario más cercano para el diálogo polifónico y para el cuestionamiento de la supuesta superioridad del conocimiento científico. 


\section{Metodología}

Las reflexiones que expongo en este artículo son producto de un entorno fecundo de conversación al interior del equipo de la línea "Conflictos sociales y armados. Abordajes psicosociales hacia la construcción de culturas de paz" del Doctorado en Psicología de la Pontificia Universidad Javeriana, Sede Bogotá. En este escenario he tenido la oportunidad de cuestionar mis presupuestos, de implicarme en discusiones sobre múltiples experiencias y fenómenos, de escuchar, aprender, conversar, construir conocimiento y trazar surcos en el pensar junto con colegas que cuentan con amplia experiencia en el abordaje de los conflictos y las paces. Las reflexiones se nutren también de mi propia experiencia de investigación sobre los procesos de reintegración de excombatientes, así como de la revisión crítica de los postulados que esgrimen los autores con los que dialogo a través de un andar frente al cuál hago hoy una breve pausa para presentarles lo que he ido comprendiendo en el camino.

\section{Resultados}

Este apartado se estructura a partir de un conjunto de premisas que abren senderos y escenarios de reflexión, esperando estimular la comprensión y la conversación en torno a las condiciones de posibilidad de un enfoque para la comprensión y el fortalecimiento de las paces cotidianas. Es decir, en estricto sentido, por el tipo de artículo que es este, se podrían entender los siguientes "resultados" como comprensiones transitorias o resultados preliminares del pensar.

\section{Premisas para un enfoque de paces cotidianas}

\section{Premisa No. 1.}

Es necesario pensar críticamente el campo teórico-práctico de los conflictos y las paces desde una perspectiva transdiciplinar y multidisciplinar de los fenómenos, las actuaciones y las relaciones de poder.

Detengámonos en el examen de los distintos componentes de esta premisa. Como punto de partida, es importante reconocer que los abordajes de los conflictos y las paces se han configurado como un campo problemático de trabajo que implica tanto la investigación, la reflexión y la teorización, como la actuación, el acompañamiento o la intervención. El hecho de configurarse como campo indica una condición transdisciplinar insoslayable. Es decir, ningún trabajo monodis- 
ciplinar, e incluso interdisciplinar, es suficiente para abordar las temáticas más pertinentes de este campo de estudios (Flórez-Malagón, 2002).

Aun cuando históricamente los estudios sobre conflictos y paces tienden a ubicarse predominantemente en disciplinas como la ciencia política, la economía, la sociología y la historia, entre otras, ninguna de ellas puede abarcar ni agotar este $c a m p o^{1}$. Ninguna forma de intervención disciplinar en este campo puede comprenderse como una entidad aislada y autosuficiente, en la medida en que sus discursos y prácticas se configuran dinámicamente al entretejerse con otras disciplinas, así como con los contextos y los sujetos involucrados.

De acuerdo con lo anterior, se entiende que este campo, emergente en la segunda mitad del siglo XX, desborda las "fronteras" de las distintas ciencias sociales, lo que a su vez genera cuestionamientos, transformaciones, rupturas e innovaciones a nivel ontológico, epistemológico, metodológico y axiológico. Siguiendo a Flórez-Málagon (2002), se puede afirmar que la configuración de este campo permite formular una crítica a la jerarquía interna de las disciplinas, a la fragmentación de los saberes y a la problemática separación entre la actividad cognoscitiva, la ética, la estética y la ontología. Intentos por solventar dicha separación se pueden encontrar en obras de autores como Alejandro Castillejo (2000), Arturo Escobar (2015) y John Paul Lederach (2016). Las paces, como los conflictos, no funcionan como "objetos disciplinares", sino que implican un desdibujamiento y una crítica de esa lógica. Antes bien, representan escenarios dinámicos de convergencia, por lo que demandan cruces de fronteras, pensamientos de frontera, comprensiones nómadas. Los campos se configuran a partir de nuevos lenguajes, nuevos registros de conocimiento y escritura que generan la reorganización permanente del saber y el establecimiento de nuevas pragmaticidades (Flórez-Málagón, 2002). Otras características de los escenarios de transdisciplinariedad son la complejidad, la heterogeneidad, la no linealidad, el diálogo entre lo local-regional-global y la vocación política. Vocación que genera tensiones y vertientes al interior de los campos. En el campo que nos ocupa esto se manifiesta, por ejemplo, en la tensión entre una paz (neo)liberal y las paces cotidianas.

La lógica de un campo transdisciplinar obliga a reconocer que, más allá de algunos referentes mainstream, se trata de un escenario en devenir, emergente, que no se ha estabilizado ni sus fundamentos están por completo delimitados. A esto contribuye la dimensión singular o existencial de los fenómenos sobre los que trabaja. En este caso, los conflictos y las paces (fenómenos situados, contextualizados, históricos) dinamizan permanentemente el campo.

1. De hecho, el predominio de este tipo de disciplinas puede relacionarse con el privilegio de una mirada macro que se alinea con una lógica de gobernanza de los conflictos desde escenarios e instituciones transnacionales. 
De otra parte, la perspectiva transdisciplinar se articula con una mirada multiescalar dinámica e integrativa que invita a ejercicios permanentes de abrir y cerrar la lente de comprensión para desplazarse entre el estudio micro, meso y macro de los procesos y contextos sociales. Esta mirada no se enfoca únicamente en los procesos y lógicas que ocurren en cada escala, sino que busca identificar el entre de las distintas escalas, es decir, la manera en que se relacionan e influyen mutuamente. Los conflictos y las paces se configuran dinámicamente en la interacción entre distintas escalas (local, regional, nacional, transnacional-global).

Lo anterior invita a considerar tanto las paces cotidianas en sí mismas y en sus relaciones con otras escalas y fenómenos, como los contextos externos y la manera en que inciden en la configuración, el devenir, las tensiones y las relaciones de poder que atraviesan las experiencias de paz a escala local.

Esta última consideración permite abordar otro aspecto que ilumina la premisa, a saber, las relaciones de poder. Se trata de un campo por completo atravesado y configurado a partir de las lógicas y dinámicas de poder. De ahí que en este artículo no profundizo en lo que podría parecer una obviedad, a saber, que los conflictos y las paces emergen, devienen y se concretan a partir de un determinado entramado de relaciones de poder. Antes bien, me enfoco en una mirada a la geopolítica del conocimiento que atraviesa el campo de los estudios sobre conflicto y paz. Esto lo exploro a partir de la siguiente premisa. Por lo tanto, es importante señalar, en relación con el tema de las relaciones de poder en la lectura de las paces cotidianas, que resulta fundamental incorporar comprensiones sobre los factores que han generado conflictos y la emergencia de violencias.

La perspectiva multiescalar integrativa también debe guiar la comprensión de los conflictos y las violencias, de manera que se evite despolitizar las paces cotidianas o desplazar la responsabilidad de las violencias a los sujetos que coexisten y habitan los territorios en los que se han configurado históricamente y de forma interrelacionada distintas conflictividades.

Por último, es fundamental resaltar el uso del plural para referirse al conflicto y la paz. Las paces, como los conflictos y las violencias, son diferenciales, interseccionales, territorializadas, corporizadas, situadas, singulares. El uso del singular para referirse a la paz resulta sintomático de una lógica de gobernanza global que busca encauzar la fuerza del torrente social que implican los conflictos y las posibilidades de transformación política que abren y prefiguran, a través de un modelo Estado-céntrico, institucionalizado, burocrático y funcional a la reproducción de sociedades neoliberales ancladas en el mercado global y en la promesa de progreso. Hablar de paces invita a romper con la idea de que existe una Paz ideal e igual para todas las sociedades, un camino que se debe transitar para alcanzarla y unos profetas que conocen la manera adecuada de conducir a cualquiera hacia la tierra prometida de la paz (neo)liberal. 
El uso del plural para referirse a la paz puede entenderse en el marco y el espíritu de un giro hacia el pluralismo y la multiculturalidad que ha llevado a hablar de identidades, subjetividades, géneros, etc. En las reflexiones de Francisco Muñoz (2001, s. f.), uno de los precursores de la pluralización de la noción y la comprensión de la paz, y en particular en su idea de paz imperfecta, podemos encontrar algunos motivos fundamentales que resaltan la importancia del uso del plural en el abordaje de las paces.

Con la noción de paces imperfectas Muñoz (2001) pretende abrir los significados de la paz, entenderla como procesal, inacabada, inmersa en la incertidumbre y en la complejidad; liberarla de la orientación negativa; identificarla con la condición humana y las condiciones particulares de existencia, abriendo así las posibilidades reales de pensamiento y acción basadas en las realidades que vivimos; reconocer que existen muchos espacios donde se producen regulaciones pacíficas de los conflictos, así como las aportaciones que cada sujeto y cada cultura puede hacer a su paz, en otras palabras, descentrar la comprensión y la construcción de paz. En definitiva, el uso del plural, la apuesta por las paces, conlleva la necesidad de debatir, repensar y resignificar los presupuestos ontológicos, axiológicos, epistemológicos, metodológicos y prácticos del campo teórico-práctico de los conflictos y las paces.

\section{Premisa No. 2.}

Desde una perspectiva de geopolítica del conocimiento es posible evidenciar un proceso de colonización en el campo teórico-práctico de conflicto y paz del Norte hacia el Sur.

Juan Daniel Cruz y Victoria Fontan (2014) postulan y argumentan que históricamente el Norte ha funcionado como un centro a partir del cual se han desarrollado el pensamiento y las prácticas sobre la paz que predominan actualmente en el Sur. Se trata, según estos autores, de una dinámica de colonización de la episteme latinoamericana sobre conflicto y paz, al igual que ocurre en otros campos. El proceso colonizador pasa por la imposición, por poderes hegemónicos (nacionales y transnacionales), de discursos, prácticas y lógicas verticales (topdown) en la academia, las instituciones, los gobiernos, las comunidades y diversos terrenos prácticos. La paz que es impuesta por medio de estas lógicas verticales, desde arriba, es denominada por Cruz y Fontan (2014) como paz liberal.

En el campo sobre conflictos y paces se "venden" e implementan discursos de "paz" mainstream que mantienen el núcleo de poder de los Estados y las élites. Cruz y Fontan (2014) sostienen que estos discursos y sus prácticas invisibilizan y niegan voces, idiosincrasias y contextos locales y comunitarios, así como la existencia de paces que surgen desde lo local. Esto hace que el papel protagónico 
de las personas y comunidades en la construcción de "su” paz sea relegado a un rol subalterno frente a la dominación del Estado, sus instituciones y las organizaciones internacionales.

La apuesta desde este tipo de perspectivas críticas sobre la geopolítica del campo de estudios en conflicto y paz, apunta a desplegar ejercicios de decolonización de la episteme latinoamericana. En palabras de Cruz y Fontan (2014) esto implica decolonizar los supuestos desde, para y sobre la paz impuestos desde el Norte y, conjuntamente, reivindicar que existen tipos de paces que surgen de lo local y en la cotidianidad. Se apuesta por reconocer y posicionar la idea de que "la paz que ya existe a nivel local no tiene que ser construida de acuerdo con los valores y el entendimiento que no son propios de ese entorno" (Cruz y Fontan, 2014, p. 142).

Para estos autores se debe promover una pedagogía crítica del colonialismo y la creación de conocimientos decolonizados sobre los conflictos y las paces a partir de un posicionamiento desde el Sur global. Tal pedagogía permitiría visibilizar, celebrar y repensar los tipos, prácticas y modelos propios de paz que se vienen creando desde abajo, desde lo local-cotidiano. En este punto es necesario destacar que estos escenarios, por su misma situación de marginalidad, exclusión y subordinación, pueden llegar a enfrentar mayores retos y complejidades en materia de conflictividades y construcción de paz, por lo que requieren y pueden por sí mismas desarrollar alternativas complejas, creativas y que puedan dar cuenta de la singularidad de cada caso. Esto llevaría a problematizar la insistencia en considerar la producción de modelos desde el Norte Global y su adopción como el camino "ideal”, más “avanzado” y “adecuado” para "gestionar” las conflictividades y construir "la paz".

Es importante, por todo lo anterior, preguntarse por aquello que representan el Norte y el Sur en la lógica de una propuesta decolonial como la de Cruz y Fontan (2014). Hablar en términos de Norte y Sur nos posiciona en una comprensión de la geopolítica que identifica una dinámica históricamente configurada en la que las relaciones entre las distintas sociedades y países responden a una lógica de centro-periferia. Se trata de una lógica que opera según relaciones de poder en las que las sociedades y los países que encarnan el centro tienen mayor capacidad y probabilidad de gobernar a las periferias. Se gobierna sobre múltiples campos, escenarios y escalas, a partir de articulaciones complejas de lo político, lo económico, lo social y lo cultural.

Al interior de las sociedades periféricas se reproduce la misma lógica de centro-periferia, por la cual, algunos sectores y territorios se erigen como centros que establecen una relación de gobierno con y sobre las periferias. Dichos centros locales, regionales y nacionales pueden llegar a alinearse con los centros transnacionales-globales y favorecer así la reproducción de un determinado orden de 
cosas hegemónico. Es importante advertir que en las relaciones de poder que se establecen en esa lógica geopolítica de centro-periferia siempre hay lugar para la emergencia y el ejercicio de la resistencia. Nunca hay una dominación total y permanente.

Está claro que las nociones de Norte y Sur representan algo más que una ubicación geográfica y una dinámica geopolítica a escala internacional. Lo que representan el Norte y el Sur, esto es, posiciones dinámicas en una lógica vertical de relaciones de gobierno, permite advertir que la posición del Norte puede reproducirse en escalas nacionales, locales e interpersonales.

La ontología política propuesta por Arturo Escobar (2015) ofrece más elementos para ampliar la comprensión del Norte y el Sur como un modelo o una perspectiva para interpretar críticamente las relaciones de poder en una clave multiescalar integrativa. La noción de ontología permitiría entender el Norte y el Sur como mundos o conjuntos de mundos articulados a través de una gramática particular. Una gramática, según Joan-Carles Mèlich (2014, 2012), es un universo simbólico-normativo (signos, símbolos, creencias, mitos, rituales, hábitos, valores, marcos, prácticas, costumbres y epistemes) que estructura las experiencias y la vida cotidiana, que ordena, clasifica y conceptualiza, que incluye y excluye, que prescribe y, de esta manera, configura un mundo dado por supuesto. Hay un mundo en cada gramática, por eso al heredar una gramática también se hereda un mundo, uno que se está haciendo y que nunca está hecho del todo; que nos posee, nos determina, nos sitúa, pero que también podemos transformar y configurar.

El Norte y el Sur representan mundos, formas de vida, de ser, de relacionarse, de construir comunidad, de asumir el desarrollo, de organización socio-política, etc., cuya configuración está mutuamente condicionada o determinada. Es decir, en este modelo, no tiene sentido pensar el Sur o el Norte en sí mismos, dejando de lado al otro posicionamiento. La configuración y el funcionamiento de un Norte están condicionado por la configuración y el funcionamiento de un Sur, y viceversa. Estamos ante un modelo relacional que, como diría Arturo Escobar (2015), postula que nada ni nadie preexiste a las relaciones que lo constituyen. Esta perspectiva crítica, que evidencia la manera de estructurar relaciones a partir de la lógica norte-sur, llama la atención sobre cómo las relaciones que nos constituyen pueden estar atravesadas por dinámicas de gobierno que les dan una forma vertical. Verticalidad que desequilibra, que establece formas de colonización, control, sumisión, desigualdad (ontológica, política y económica) y explotación del Norte hacia el Sur.

Ahora, no se trata de buscar que el Sur devenga el nuevo Norte. De lo que se trataría, siguiendo a Escobar (2015) y a Cruz y Fontan (2014), es de decolonizar las relaciones Norte-Sur, de deconstruir y subvertir esa lógica relacional. En 
últimas, se aspira a que no exista la situación a partir de la cual se debe hablar de un Norte y un Sur. En la ontología política de Escobar (2015) esto se traduce en la afirmación y preservación del pluriverso. El modelo Norte-Sur devela la existencia de múltiples mundos que se agrupan en una dinámica agonística en la que uno de esos mundos, o un conjunto de ellos, intenta posicionarse como "el" Mundo hacia el cual, o en el cual, todos los mundos deberían converger. La ontología política re-sitúa al Norte, al mundo moderno (globalizado, neoliberal-capitalista, racionalista, "civilizado", individualista, dualista, signado por el mito del progreso), como un mundo entre muchos otros mundos. Esto representa la subversión del modelo Norte-Sur, a través de la defensa del pluriverso.

De esta forma, se puede sortear la aporía y la contradicción que supondría afirmar el Sur Global (como un nuevo Norte) sin estallar la lógica relacional Norte-Sur. Pensar las paces desde abajo, desde lo local y lo cotidiano, sin subvertir esa lógica, quizás lleva a autores como Cruz y Fontan (2014) a postular una paz subalterna, término que deliberadamente he buscado evitar para la fundamentación de un enfoque de paces cotidianas. La noción de subalternidad, si bien puede cumplir una función, por ejemplo, desde la perspectiva de la construcción de una conciencia de clase, puede también contribuir a la configuración de identidades ancladas, ontológica y epistemológicamente, en la polaridad y la reproducción del modelo Norte-Sur. Instalarse en la polaridad resulta contrario a un enfoque de paces cotidianas que apuesta más por el diálogo de saberes, por los encuentros y la construcción conjunta con los distintos agentes e instituciones que están presentes (e incluso ausentes) en un mundo de la vida atravesado por la conflictividad violenta.

El enfoque de paces cotidianas que aquí perfilo encuentra un terreno fértil en la ontología política de Arturo Escobar (2015). Construir paces en una escala cotidiana, en el mundo de la vida, conlleva, sin agotarse en ello, el cuidado del pluriverso. Esto es, la defensa activa de los muchos mundos que, interconectados, habitan el planeta. Se trata de la reivindicación de la autonomía para cambiar las normas (la gramática) de un mundo desde adentro y en sus propios términos. La afirmación del pluriverso implica deconstruir la dinámica relacional que favorece la colonización de un mundo por otro y estallar el mito del "Mundo ideal y feliz" a partir del cual todos los mundos deberían constituirse a su imagen y semejanza.

Por lo dicho hasta el momento, se comprende que una condición de posibilidad de las paces cotidianas se encuentra en la crítica lúcida y desacralizadora de los evangelios, los profetas y los dogmas sobre los cuales se edifica e inocula el mito de una modernidad que opera como una religión antropoteísta. Esta religión democrática, como la denominara Nicolás Gómez (2001; 2010) y como han advertido varios pensadores perspicaces como Walter Benjamin (1996) y Max Weber (2010) está consagrada a un perverso e imperativo deber: el capital debe circular, reproducirse, expandirse, multiplicarse. Y por esta meta todo puede ser sacrifi- 
cado. La defensa del pluriverso antepone el cuidado de la vida a este imperativo impuesto por "el único dios completamente falso". En este cuidar la vida y los mundos, las paces cotidianas pueden encontrar recursos, senderos, territorialidades e interacciones propicias para germinar.

\section{Premisa No. 3.}

El estudio y la práctica de la construcción de paz han experimentado un giro tecnocrático, una sobrevalorización del experto y la imposición de una lógica vertical (top-down) centrada en instituciones.

Una estrategia que hace parte de la forma en que opera la lógica colonizadora en el campo objeto del presente trabajo implica, siguiendo a Roger Mac-Ginty (2014) y a Cruz y Fontan (2014), la importación e implantación de modelos, de una forma vertical (top-down), tecnocrática e institucionalizada. Se trata de modelos pensados y probados para otras sociedades y contextos. Esta estrategia conlleva la estandarización y profesionalización de gran parte del discurso, las comprensiones, las medidas, las actividades y las prácticas relacionadas con la construcción de paz.

Frente a este panorama un enfoque de paces cotidianas debe asumir una postura crítica y propositiva. Uno de los focos de la crítica es la posición de expertos que la lógica colonizadora incentiva en los profesionales de la construcción de paz y la idea de que la "experticia" es exógena, relegando así a los actores locales a la posición de víctimas pasivas y receptores que carecen de la agencia para trasegar su camino sin ayuda externa (Cruz y Fontan, 2014; Tovar, 2013). La lógica colonizadora deriva, en este escenario, en la configuración, por un lado, del rol de "expertos-salvadores" (los profesionales que diagnostican, recetan, guían e imponen prácticas) y, por otro, el rol de inexpertos que deben ser "salvados". Para Cruz y Fontan (2014) la dinámica relacional que promueve el asumir estos roles podría comprenderse como una forma de gobernanza terapéutica, en la cual

Los modelos externos son la receta, los gobiernos y políticas de paz son los médicos, las agencias de paz son los buenos enfermeros, las comunidades los enfermos que "no saben" por qué se han enfermado y tampoco conocen (ni deben atreverse a conocer) una receta diferente a la recomendada por el doctor (p. 137).

La gobernanza terapéutica genera lazos de dependencia, subordinación y asistencialismo, así como intervenciones que resultan invasivas en la medida que alteran las rutinas y el ambiente local, desconocen los recursos instalados, no consultan la voluntad, la disponibilidad y las necesidades sentidas de las personas y sus comunidades (Tovar, 2013). Esto contribuye a silenciar y marginalizar voces e iniciativas locales, en pro de una paz impuesta, lo cual puede generar 
consecuencias desastrosas en relación con el conflicto que se procura gestionar (Cruz y Fontan, 2014; Tovar, 2013).

Desde un enfoque de paces cotidianas se propende por desnaturalizar (historizar) y deconstruir el rol o la posición de sujeto del experto-salvador. Esto conlleva enarbolar la igualdad ontológica entre los sujetos cognoscentes y los sujetos conocidos (Vasilachis, 2006). En virtud del reconocimiento de dicha igualdad, el "otro" hacia el cual se dirigen las estrategias de conocimiento e intervención, aparece como alguien que tiene igual capacidad de producir un saber valioso, implique o no el método científico, así como de influir en el sujeto cognoscente (Vasilachis, 2006). En esta línea, Claudia Tovar (2013) afirma la importancia de los gestos genuinos de humildad y curiosidad como reacción a la omnipotencia que suele ser frecuente entre profesionales que trabajan con poblaciones vulnerables. Esto exige, por su puesto, una actitud reflexiva y autocrítica permanente, por parte de los profesionales, frente a los supuestos ontológicos, axiológicos, epistemológicos y metodológicos que orientan las propuestas de comprensión y acción que enarbolan. A esto se suma la importancia de reconocerse como un sujeto cognoscente situado, interseccional y enmarcado por relaciones de poder.

De acuerdo con lo anterior, la perspectiva que asume un enfoque de paces cotidianas reivindica la capacidad de agencia de los individuos y las colectividades, así como los saberes y recursos idiosincráticos instalados y emergentes en los contextos de trabajo (Mac-Ginty, 2014; Tovar, 2013). De manera que resulta necesaria la transgresión de las formas convencionales de producir conocimiento y prácticas de trabajo en el campo de los conflictos y las paces (Cruz y Fontan, 2014). La construcción de conocimiento y planes de trabajo en el terreno derivan en una lógica que privilegia la cooperación, el diálogo horizontal y los mecanismos de retroalimentación permanente. Se resalta también la importancia de recoger, analizar, hacer visibles y celebrar los aprendizajes en materia de construcción de paz en experiencias cotidianas (Hernández, 2013).

Celebrar las experiencias cotidianas en el campo de la construcción de paces ofrece la oportunidad de que emerjan nuevas preguntas, demandas, alternativas, métodos, metáforas y perspectivas para la transformación de los conflictos, la regulación y la superación de las violencias. De esta forma, los propios significados de las experiencias cotidianas en construcción de paz se erigen como un faro guía de la teorización-acción (Tovar, 2013). Al respecto, Mac-Ginty (2014) llama la atención sobre cómo la aparente banalidad de lo cotidiano nos reta a pensar creativamente sobre las perspectivas y metodologías que pueden permitir capturarlo; diría yo, que permitan aprehender lo cotidiano, sin colonizarlo ni someterlo. 


\section{Premisa No. 4.}

La escala de lo cotidiano ofrece experiencias, prácticas, recursos, perspectivas e interpretaciones sobre los conflictos y las paces que pueden confrontar la lógica hegemónica propia de un modelo geopolítico Norte-Sur.

$\mathrm{El}$ enfoque del cual he expuesto algunos de sus fundamentos reivindica la escala cotidiana, local-comunitaria, sin por esto desdeñar las otras escalas y las múltiples posibilidades de interrelación, como es propio de lo que he denominado perspectiva multiescalar dinámica e integrativa. Esta reivindicación implica evidenciar y celebrar la capacidad de agencia y las propias iniciativas de construcción de paces heterogéneas que se configuran y tejen desde abajo, desde lo local, así como las experticias e innovaciones que no son producto de las academias, las instituciones y los gurús de la resolución de conflictos (Mac-Ginty, 2014). Se trata de posicionar así la idea de que los expertos externos y sus recursos no son una condición necesaria y suficiente, no son indispensables, para "traer la Paz" a las comunidades y dar forma al mundo de la vida de las personas.

Esto no quiere decir que se rechace la posibilidad de diálogo con agentes externos, pero sí que, en dado caso, las conversaciones se harían en un escenario horizontal, de mutuo reconocimiento, en el que las personas y sus comunidades puedan erigirse como agentes activos de la construcción de sus paces. Por su puesto, esta postura conlleva un profundo cuestionamiento a la primacía del Estado y las instituciones formales (nacionales e internacionales) como los principales referentes para la investigación-intervención en el campo de conflictos y paces. También implica preguntarse por el tipo de relaciones de poder que se construyen a partir de la cooperación externa que llega a los territorios con recursos muchas veces largamente anhelados por las comunidades. De ahí la importancia de indagar la manera en que distintas comunidades han logrado resolver estas tensiones sin rechazar el diálogo y la interacción con agentes externos y sin permitir la cooptación de la construcción de sus paces cotidianas.

Roger Mac-Ginty (2014) advierte que, por posturas como las acabadas de presentar, la agenda de un enfoque de paces cotidianas es potencialmente $s u b$ versiva porque lleva el campo de las paces más allá y más acá de los programas, los proyectos, las iniciativas, los recursos, las ONG y las organizaciones internacionales que colonizan y gestionan muchos de los escenarios de construcción de paz. Con este autor se puede afirmar entonces que lo cotidiano-local, no es un epifenómeno de fuerzas estructurales profundas, antes bien, es una fuerza generativa en sí misma y resulta constitutivo de lo nacional y lo transnacional. Esta perspectiva, diría Mac-Ginty, (2014), contribuye a contrarrestar un fatalismo asociado al poder creciente de las aproximaciones tecnocráticas, Estado-céntricas e institucionalizadas a la paz. Fatalismo que se asocia con la percepción de 
una ausencia de control y agencia frente a las propias conflictividades y el propio mundo de la vida.

Descentrar el campo de trabajo en conflictos y paces de la lógica vertical-institucional va de la mano con una crítica al abordaje de estos fenómenos centrado en la violencia, aún más en la violencia directa. Centrarse en la violencia puede generar escepticismo y desesperanza frente a las posibilidades y alternativas para la construcción de paz. De igual forma, desestimar las formas de violencia cultural y estructural puede ser en sí una forma de violencia que las perpetúa manteniendo así condiciones que hacen que la posibilidad de escaladas de violencia directa permanezca latente.

En consecuencia, un enfoque de paces cotidianas exigirá siempre una comprensión compleja e integral de los distintos aspectos de los conflictos, en clave de construcción de paz. Dentro de aquella se encuentra la construcción de representaciones precisas y complejas del “otro” que vayan más allá de las caricaturas unidimensionales (Mac-Ginty, 2014). Resulta entonces indispensable apuntar a la deconstrucción de las historias dominantes y saturadas del problema, permitiendo ver que los conflictos no son totales, que siempre existen historias alternativas, recursos, resistencias y experiencias de paz aún en los momentos más álgidos y virulentos de las confrontaciones.

Desde la propuesta de Lederach (2016) lo anterior se conecta con la idea de apostar por el fortalecimiento de una imaginación moral que desafía lo que parece punto muerto y estructuralmente determinado, que irrumpe en nuevos territorios, desborda las opiniones existentes sobre la realidad percibida, abre lo que se determina como posible, contribuye a materializar posibilidades, a crear lo que no existe o a potenciar lo que existe sin la fuerza necesaria para generar mayores transformaciones. Por el sendero de Lederach (2016), el enfoque de paces cotidianas apuesta por esa capacidad de imaginar y generar respuestas e iniciativas constructivas que, aun estando enraizadas en los retos cotidianos de la violencia, trasciendan y, en última instancia, rompan los amarres de esos patrones y ciclos destructivos.

El enfoque de paces cotidianas conlleva el reto de lograr aprehender lo cotidiano en y desde sus propias poéticas, sus ethos, sus pathos, sus estéticas-políticas (formas de vida). Resulta indispensable que los propios sujetos, situados e interseccionales, que construyen día a día su cotidianidad con otros, sean los protagonistas de la interpretación y transformación de ese mundo de la vida. Ahora bien, esto no puede derivar en una idealización de lo local-comunitario. Los sujetos muchas veces encarnan, reproducen y se pueden ver "favorecidos" por las violencias que atraviesan su cotidianidad. De ahí que los agentes externos, siempre y cuando asuman una postura que reconozca la igualdad ontológica y garantice los escenarios horizontales, tienen un rol significativo para apoyar a 
los sujetos en sus ejercicios de comprensión y transformación de sí mismos y de sus circunstancias.

El trabajo de comprensión que he perfilado hasta ahora como insignia del enfoque de paces cotidianas puede entenderse también como una labor de historizar lo cotidiano, en la senda de la ontología del presente que articula toda la obra de Michel Foucault (2014, 2004). Comprender los presentes implica ejercicios genealógicos de problematización de las dinámicas, las experiencias, las afectividades, los significados, las instituciones, las epistemes, los dispositivos, los discursos, las tecnologías, las relaciones de poder y las subjetividades que configuran y se re-configuran en lo cotidiano. Los ámbitos de encuentro cara-a-cara en los que se negocian significados, se implementan tecnologías de gobierno y devienen procesos de subjetivación (Castillejo, 2017), adquieren en este enfoque un renovado y protagónico estatus epistemológico y ético-político.

\section{Premisa No. 5 .}

El campo semántico sobre el cual se erige un enfoque de paces cotidianas reivindica una paz cotidiana frente a una paz (neo)liberal.

En esta última premisa abordo el concepto central del enfoque que he ido perfilado a partir de las premisas anteriores. La noción de paz cotidiana o paces cotidianas estructura dicho enfoque y se contrapone (en lo ontológico, epistemológico, metodológico y ético-político) a una forma de paz (neo)liberal.

De acuerdo con Juan Daniel Cruz y Victoria Fontan (2014), una paz liberal o (neo)liberal es aquella que es impuesta desde arriba, en una lógica vertical, colonizadora, por medio de prácticas hegemónicas en las que lo externo (nacional o transnacional) somete lo local-cotidiano. Este modelo de construcción de paz se inscribe en lo que Alejandro Castillejo (2017) denomina como gobernanza global de las transiciones políticas (en situaciones de conflicto armado o de regímenes dictatoriales). Para Cruz y Fontan (2014), como precisé en el desarrollo de la tercera premisa, se trata de una gobernanza terapéutica.

Una paz (neo)liberal se configura a partir de la mirada universalista y administradora que asume la $\mathrm{Paz}$ como un remedio mecánico para el Conflicto. También se organiza en torno a los Estados y sus territorios, al desarrollo socioeconómico neoliberal, las organizaciones internacionales, las élites burocráticas y las clases políticas y empresariales. Esta dinámica, como he mencionado anteriormente, deriva en la marginalización y/o cooptación de las voces y los procesos locales. Situación que puede profundizar los conflictos e instalar la ilusión de que la construcción de paz obedece exclusivamente a fórmulas y réplicas de modelos externos, así como a la agencia redentora de los expertos de la Paz. El enfoque de paces cotidianas se contrapone a todas estas lógicas, perspectivas e implicaciones de la paz (neo)liberal. 
En contraste con una paz (neo)liberal, Roger Mac-Ginty (2014) define paz cotidiana como las prácticas, técnicas y normas desplegadas por los individuos y los grupos en sociedades profundamente divididas para evitar y minimizar el conflicto y las situaciones difíciles, tanto inter como intragrupal. Considero que esta definición se puede reformular y complementar para entender las paces cotidianas como conjuntos dinámicos, situados (contextualizados) y ritualizados de discursos, normas, métodos, prácticas y técnicas que utilizan en la vida diaria individuos y colectivos en el marco de sociedades profundamente divididas, propensas a la violencia directa y con expresiones de violencia estructural, con el fin de gestionar sus conflictos, crear y cuidar formas no violentas de vida e interacción con otros.

Asumir esta noción de paz cotidiana implica reconocer que la cotidianidad está gobernada por conjuntos de reglas, el mundo social es fluido, los grupos son heterogéneos, los factores ambientales son de suma importancia (Mac-Ginty, 2014) y la dominación nunca es total; es decir, siempre hay posibilidades de agencia, de resistencia y acción poiética (involucra imaginación moral, innovación, improvisación y creatividad). Una paz cotidiana se debe fundamentar en y permitir la agencia. Su origen es local-comunitario y funciona en una lógica horizontal del tipo de abajo hacia arriba (bottom-up), siempre en el marco de relaciones de poder que son determinantes para su comprensión y configuración.

Por lo anterior, la paz no siempre resulta obvia, incluso puede y tiende a operar de forma casi clandestina, en una esfera informal que no es sujeto inmediato de los mismos controles que moldean los proyectos formales (ciclos de presupuesto, mecanismos de reporte, fechas límite, etc.) (Mac-Ginty, 2014). En el ámbito de lo informal emergen sistemas de gobernanza no escritos y en constante evolución que se aplican a las relaciones inter e intragrupales (Mac-Ginty, 2014).

De esta manera, una paz cotidiana se aleja de las nociones, las lógicas, los programas, los proyectos, las instancias y organizaciones Estadocéntricas, institucionalizadas, tecnocráticas y burocráticas (élites de la construcción de paz). Aquí se encuentra uno de los principales retos para una paz cotidiana: lograr entablar diálogos y relaciones de cooperación con instancias externas (nacionales e internacionales) sin perder su autonomía y su capacidad de agencia, sin ceder a la cooptación y a la colonización, logrando gestionar estratégicamente los riesgos para la vida de quienes encarnan ese modelo afincado en la cotidianidad local. El objetivo se encuentra en que los diálogos y otras interacciones con élites e instituciones puedan aumentar la probabilidad de que una paz cotidiana se posicione y perdure en el tiempo.

Es importante entender, siguiendo a Mac-Ginty (2014), que una paz cotidiana es fluida y puede pensarse como un continuo; con una versión minimalista que concierne a la supervivencia (evitar o calmar el conflicto y la violencia direc- 
ta -paz negativa-) y una visión amplia (acciones más positivas y ambiciosas de transformación o impacto cualitativo en la naturaleza del conflicto -paz positiva-). La fluidez puede significar, por otra parte, que una paz cotidiana puede ser posible en algunos periodos e imposible en otros, fuerte en algunos aspectos pero débil en otros. También se trata de una paz interseccional (responde a aspectos de clase, género, raza, religión, edad, etc.), diferencial, territorializada, corporalizada y dialógica (se soporta en la interacción, el reconocimiento social, la reciprocidad, los parámetros compartidos y las respuestas sociales). En distintos aspectos se trata de una paz parresiaca.

De acuerdo con Michel Foucault (2010), la noción de parresia tuvo un extenso uso en la antigüedad greco-latina. Con esta noción se connotaba una relación vital, antes que formal, del sujeto con el discurso que enarbola. Esto quiere decir que su discurso no es "verdadero" porque obedece a un conjunto de reglas técnicas, sino que lo es porque se encuentra avalado por el modo de vida de quien lo enuncia. El parresiasta mostraba un "coraje de la verdad" al no temer el riesgo vital que pudiera suponer comportarse de acuerdo con su discurso. Se trata de una correspondencia entre, acción, discurso y ethos. El parresiasta desnuda, desafía y confronta al político, al técnico de la gestión de lo social, con su "decir veraz", a través de su forma de vida.

En ese sentido, planteo que una paz cotidiana resulta parresiaca, pues se trata de una paz que no se configura y posiciona en la cotidianidad partiendo de modelos formales y discursos técnicos, sino que su potencia se encuentra en las formas de vida, en las microsocialidades, las narrativas, las experiencias y los significados de sujetos y comunidades que le apuestan a estrategias para la gestión de sus conflictos, las cuales se alejan de las lógicas de una paz (neo)liberal.

Por lo tanto, su enseñanza responde más a la observación sensible, la intuición, el ensayo y el error, las diversas formas de transmisión cultural y el encuentro de los sujetos inmersos en las situaciones de conflicto, que a los manuales o a la literatura académica confinada en artículos Q1 y Q2. En los contextos de profunda división sociopolítica en que se ponen en juego las iniciativas de paz cotidiana, como lo menciona Foucault a propósito del parresiasta y lo advierte Lederach (2016) sobre la imaginación moral, se requiere coraje, voluntad de arriesgar y de adentrarse en lo desconocido sin mayor garantía de éxito o seguridad. Una paradoja de los escenarios de conflicto, dice Lederach (2016), es que la violencia es lo conocido, el misterio es la paz.

Este aspecto parresiaco, en el que las apuestas de paz devienen formas de vida con otros en la cotidianidad, así como su origen local-comunitario, puede dar a una paz cotidiana mayor autenticidad y legitimidad frente a las iniciativas importadas y hegemónicas. Siguiendo a Mac-Ginty (2014), se trata de una forma 
de paz que puede contribuir a evitar la escalada, la hybris del conflicto, a mantener algo de "civilidad" y a introducir reglas informales en situaciones críticas.

Los parresiastas, entonces, no buscaban alejarse para poder preservar su forma de vida, más bien buscaban algo que autores como Mac-Ginty (2014) y Lederach (2016) consideran indispensable para la construcción de una paz cotidiana, a saber: la conquista de un existir en la esfera pública como agentes de su propia paz. Esto implica, por ejemplo, desmonopolizar las agendas de paz de los modelos, los cronogramas y el manejo de recursos impuesto por las instituciones nacionales e internacionales (Cruz y Fontan, 2014).

Los parresiastas, con su decir veraz, con su política y su paz encarnadas en su cuerpo, en su territorio, en su forma de vida y de relación con otros, pretenden horizontalizar el campo social de las relaciones de poder. Una paz cotidiana, parresiaca, deviene así categoría, figura y ejercicio de resistencias. Resistencia frente a toda lógica y modelo de paz (neo)liberal, pero también respecto a cualquier forma de polarización, de fatalismo, de narrativa dominante, hegemónica y totalizadora del conflicto. Resistencia a las narrativas del "otro" que reproducen la desigualdad ontológica y lo representan como alguien homogéneo e invariable, irracional, peligroso, ilegítimo, indigno, con quien no se puede dialogar y en quien no se puede confiar. Resistencia como crítica a las legitimaciones e instrumentalizaciones de los conflictos y las violencias.

\section{Conclusiones}

A manera de colofón e invitación a continuar pensando un enfoque de paces cotidianas, planteo en estas conclusiones algunas reflexiones, retos, preguntas y aperturas que se derivan del desarrollo de las anteriores premisas.

Como punto de partida, considero necesario explicitar que las paces cotidianas no se circunscriben exclusivamente al mundo de la vida de poblaciones en condiciones de exclusión, discriminación, marginalidad, precariedad socioeconómica o vulneradas por la violencia directa. Una paz cotidiana puede, y muchas veces debe, involucrar a distintos sectores de la sociedad. A esto contribuye la apuesta del enfoque de paces cotidianas que aquí perfilo por despolarizar el mundo de la vida y por subvertir la lógica relacional de tipo Norte-Sur. Asumir este modelo polarizante puede llevar a que nos instalemos en un lugar de identidad subalterna y en una militancia que busca romper del todo con el arriba; con el Norte, las élites, las instituciones y el Estado (a nivel local, regional, nacional y transnacional). Al respecto, resalto la importancia de reconfigurar las relaciones 
desde y en lo cotidiano, entendido como una fuerza generativa en sí misma, pero sin "idealizarlo".

En este punto considero necesario problematizar y matizar la forma en que se presentaron algunas de las consideraciones sobre las paces cotidianas y que podrían generar la impresión de que se está proponiendo una perspectiva dicotómica que pretende encapsular las formas de construcción de paz en dos categorías o tipos ideales: las paces cotidianas y la paz neoliberal. Considero que no es viable asumir que todas las experiencias de construcción de paz puedan ubicarse o alinearse en una de esas dos formas de comprensión e interpretación.

Cada experiencia de paz, aunque en principio pueda suscitar la impresión de poder reconocerse desde una u otra forma de construir paz, puede implicar o desarrollar formas complejas de hibridación, contradicciones, continuidades y discontinuidades, desplazamientos, tránsitos y transformaciones. Pueden darse interconexiones entre las distintas formas de construcción de paz. Presencias e incidencias de las lógicas de una paz neoliberal en las experiencias de paz cotidiana, así como lógicas de una paz cotidiana influir en la manera de proceder en escenarios de construcción de paz signados por la presencia y la gestión tecnocrática.

También es importante advertir que en escalas no locales y ámbitos estatales pueden operar lógicas no neoliberales, es decir, aquellas no son necesariamente prerrogativa de la escala local-cotidiana. Creo que acercamientos fenomenológicos y etnográficos a las experiencias de construcción de paz, sin exclusión de otros enfoques metodológicos, pueden ir demarcando los propios movimientos de la comprensión y de la interpretación, así como su pertinencia para contribuir al fortalecimiento de dichas experiencias.

Por otra parte, resulta riesgoso desconocer que los conflictos, las violencias, las lógicas de exclusión, el neoliberalismo y el capitalismo, también se construyen desde el Sur, desde abajo, desde lo local. No podemos caer en la trampa de "idealizar" lo cotidiano y las estrategias comunitarias como si fueran perfectas y exentas de contradicciones, conflictos, riesgos, ideologías, intereses particulares, reproducciones de lógicas colonizadoras y efectos perversos, por el solo hecho de emerger desde abajo. Un enfoque de paces cotidianas no puede negar o desconocer la configuración histórica y la presencia de los conflictos y las violencias que pueden existir en las comunidades y en los territorios en que emergen apuestas por construir paces situadas. De hecho, es posible que un factor que avive esos conflictos sea las distintas comprensiones y apuestas sobre cómo se entienden y cómo se construyen las paces.

Pretender romper con el Estado, las instituciones, las organizaciones y las élites, puede implicar entrar en el juego del neoliberalismo, que desplaza la responsabilidad (y la culpa) del cambio y del "desarrollo" a los individuos y sus 
comunidades. Un ejemplo de lo anterior es señalado por Mac-Ginty (2014) en relación con las agendas superficiales que elevan la "resiliencia" al estatus de cura para todo (mirada ideológica que conecta neoliberalismo y comunitarismo). Antes que facilitar el "lavado de manos" de los gobiernos, un enfoque de paces cotidianas pretende construir puentes de diálogo horizontal y construcción conjunta, colaborativa y co-elaborativa entre las experiencias locales de paz y los agentes e instituciones que operan en otros escenarios y escalas. Para ello, es fundamental abogar por el reconocimiento de la igualdad ontológica para todos.

A una paz construida desde lo local le puede resultar difícil conectarse con el nivel de las élites. No obstante, algún tipo de interacción es necesaria para evitar que las élites atenten contra los procesos de construcción de paz cotidiana. En este sentido, quienes interactúen con las élites deben procurar tener en cuenta los temores y riesgos que aquellas puedan estar percibiendo, con el fin de contribuir a gestionarlos estratégicamente.

Este enfoque de paces cotidianas aboga por una mirada dinámica de las relaciones de poder que permita a las iniciativas de paz contar con más y mejores herramientas para persistir, resistir, adaptarse, fortalecerse, posicionarse e incidir en la esfera pública. Se trata también de reivindicar la legitimidad y la potencia del conocimiento que se construye desde lo local, desde quien habitualmente es puesto en la posición de sujeto conocido y enunciado. Un conocimiento no solo sobre sí mismos, sus experiencias y sus mundos de la vida, sino sobre las élites, el gobierno y, en general, sobre quienes históricamente los han estudiado, categorizado, teorizado, enunciado, modelado, calculado y gobernado.

En la vida cotidiana, en la escala de lo local, existen epistemologías, modos de pensar y relacionarse, que un enfoque de paces cotidianas debe reivindicar y poner en diálogo de saberes con el conocimiento que emana desde la academia y otras instituciones que inciden en el campo de los conflictos y las paces. Es importante que las experiencias e iniciativas de paz cotidiana implementen una mirada dinámica y estratégica de las relaciones de poder, del funcionamiento del gobierno, de los gobernantes y de otras élites, con el fin de potenciar su accionar, sus posibilidades de resistir a los intentos por cooptarlas o instrumentalizarlas, y sus alcances en términos de transformación de los conflictos y las violencias.

Esta mirada dinámica y multiescalar de las relaciones de poder recuerda la advertencia que Niccolò Maquiavelo le hace a Lorenzo de Medici en su dedicatoria al Príncipe. Allí, Maquiavelo le habla al oído a todo aquel que aspire a gobernar(se) y a moverse correctamente en los entramados de poder:

Y no quiero que se tome como presunción que un hombre de baja e ínfima condición se atreva a estudiar el gobierno de los príncipes y ponerle reglas; pues, así como los cartógrafos se sitúan en la llanura para estudiar la naturaleza de los 
montes y de los lugares altos y, para hacer lo propio con los lugares más bajos, se sitúan en lo alto de los montes, de manera similar, para conocer bien la naturaleza de los pueblos, hay que ser príncipe, y, para conocer bien la de los príncipes, hay que pertenecer al pueblo (Maquiavelo, 2010, pp. 76-77).

Este juego de perspectivas y posicionamientos resulta clave para un enfoque de paces cotidianas que enarbola la necesidad de complejizar las formas de comprensión del mundo y de sí mismos, que renuncia a miradas lineales de causalidad y a simplificar los fenómenos. Este enfoque abraza la incertidumbre que puede generar la apuesta por una problematización permanente de sus propias premisas y actuaciones. Se siente cómodo comprendiendo e interactuando con las paradojas del mundo de la vida, navegando a través del fluir de las experiencias, los significados y las metáforas siempre provisionales, así como apostando por una acción poiética que no se desconecta de las condiciones materiales de existencia.

La comprensión compleja y estratégica de los contextos y las relaciones de poder puede resultar indispensable para sortear, como señala Mac-Ginty (2014), la posibilidad, generalmente presente, de que las iniciativas de paz cotidiana se conviertan en objetivo del ejercicio de la violencia cuando amenazan las narrativas de división e incompatibilidad que se quieren perpetuar o las fronteras intergrupales, como también cuando abren posibilidades reales para las transformaciones estructurales. Incluso, miembros de la comunidad en la que nacen las iniciativas de paz cotidiana pueden también ser focos de violencia y escalada del conflicto cuando encuentran amenazante el contacto y los diálogos con agentes externos y/o ven amenazados sus privilegios. Razón por la cual, la gestión estratégica del miedo, del riesgo, de la desesperanza, de los prejuicios y de los intereses es un aspecto central de la construcción de paz cotidiana y debe hacerse tanto al interior de la comunidad, como en la interacción con agentes externos.

Quiero terminar planteando algunas reflexiones sobre el rol de la academia frente a las iniciativas de paz cotidiana, teniendo en cuenta que desde allí se contribuye a producir conocimiento y prácticas que pueden incidir en la construcción de paces en distintas escalas. Un llamado claro que se hace desde el enfoque de paces cotidianas es a cuestionar el modelo de paz (neo)liberal; éste, es un modelo cuyos presupuestos y conceptos se inscriben muchas veces en los proyectos de investigación-intervención, más aún cuando se encuentran enmarcados por financiación y/o cooperación con instituciones oficiales ${ }^{2}$. Además, tal

\footnotetext{
2. Para un abordaje crítico de este escenario y sus tensiones sugiero consultar las reflexiones consignadas en el texto "(Re)politizar la cooperación al desarrollo: Discursos, prácticas y políticas públicas para una solidaridad internacional transformadora" (Belda-Miguel, Boni y Sañudo, 2018, pp. 37-60).
} 
enfoque genera una tensión significativa para los profesionales que trabajan en el campo de los conflictos y las paces al pedirles que renuncien a la posición de expertos-colonizadores-salvadores y, aun así, exigirles que se comprometan con "hacer la diferencia" al interactuar con los sujetos y sus comunidades.

Surge entonces la pregunta por los principios y las estrategias que pueden contribuir a asumir adecuadamente dicha tensión. Esto lleva también a preguntar por el rol que puede cumplir la academia en la construcción de diálogos e interacciones entre las experiencias de paz cotidiana y las instituciones o escenarios formales, de manera que no devengan en formas, más o menos evidentes, de cooptación, colonización e instrumentalización.

También representa un reto para la academia evitar colonizar e instrumentalizar las iniciativas de paz cotidiana al priorizar los afanes de la formación, la investigación y la producción de conocimiento que privilegia los productos denominados como de "alto impacto" según la tendencia neoliberal que domina cada vez más el mundo académico.

El trabajo de campo minucioso, respetuoso de la igualdad ontológica de los sujetos cognoscentes y los sujetos conocidos (Vasilachis, 2006) y, en consecuencia, abierto a la construcción colectiva de saber, es indispensable para comprender cómo operan las iniciativas de paz cotidiana y cómo podemos contribuir humildemente a que sean exitosas y sostenibles. Aquí se encuentra otro reto relacionado con el hecho de que las actividades de paz cotidiana pueden resultar altamente localizadas y dependientes del contexto.

Se trata de la importancia de gestionar los límites sobre el cómo y dónde puede operar una determinada apuesta de paz cotidiana, así como de las posibilidades de inspirar y movilizar iniciativas en otros contextos. Más allá de las aspiraciones de replicabilidad que desvelan a la ciencia, se trata de cómo conectar con iniciativas en otros lugares y cómo poder ampliar su rango de incidencia. En otras palabras, cómo pasar de escenarios de pequeñas islas y oasis de paz, a un contexto creciente y dinámico de archipiélagos que compartan conocimientos, estrategias, aprendizajes y se potencien mutuamente.

La academia no puede limitarse a ser el traductor, el teorizador y el visibilizador de lo que emerge de lo local-cotidiano-comunitario. Debe contribuir a evitar la ruptura violenta entre lo cotidiano, lo de abajo, y las distintas instancias, instituciones y agentes que configuran un arriba en las relaciones de poder. Se trata de un compromiso con la horizontalización de las interacciones en torno a la construcción de paz, así como con la deconstrucción de falsas dicotomías y de las múltiples formas de polarización. Es la apuesta por contribuir a que los sujetos locales y las experiencias de paz cotidiana puedan lograr existir con fuerza en la esfera pública como agentes constructores de paz. Existencia que puede verse comprometida por la ruptura violenta con lo que está instalado en el arriba. 
Pero no se trata solo de contribuir a posicionar la vida cotidiana en la esfera pública; más allá de esto, implica la crítica de la falsa dicotomía que pretende diferenciar y distanciar la vida cotidiana y la esfera pública. El mundo de la vida cotidiana es una fuerza generativa constitutiva y dinamizadora de la esfera pública.

\section{Referencias}

Belda-Miguel, S.; Boni, A.; Sañudo, M. (2018). (Re)politizar la cooperación al desarrollo: Discursos, prácticas y políticas públicas para una solidaridad internacional transformadora. En G. Tonon (Comp.). Nuevas propuestas para estudiar ciencias sociales (pp. 37-60). Universidad de Palermo.

Benjamin, W. (1996). Capitalism as religion. En M. Bullock \& M. Jennings (Eds.). Selected Writings 1913-1926 (pp. 288-291). Harvard University Press.

Castillejo, A. (2000). Poética de lo otro. Para una antropología de la guerra, la soledad y el exilio interno en Colombia. ARFO Editores.

Castillejo, A. (2017). Dialécticas de la fractura y la continuidad: elementos para una lectura crítica de las transiciones. En A. Castillejo (Ed.). La ilusión de la justicia transicional: perspectivas críticas desde el Sur global (pp. 17-106). Universidad de los Andes.

Cruz, J.D.; Fontan, V. (2014). Una mirada subalterna y desde abajo de la cultura de paz. Ra-Ximhai, 1O(2), 135-152. http://www.revistas.unam.mx/index. $\mathrm{php} / \mathrm{rxm} / \mathrm{article} /$ download/71182/62885

Escobar, A. (2015). Territorios de diferencia: la ontología política de los "derechos al territorio". Cuadernos de antropología social, 41, 25-38. http:// revistascientificas.filo.uba.ar/index.php/CAS/article/view/1594/1520

Flórez-Malagón, A. (2002). Disciplinas, transdisciplinas y el dilema holístico: una reflexión desde Latinoamérica. En A. Flórez-Malagón y C. Millán (Eds.). Desafíos de la transdisciplinariedad (pp. 128-154). Pontificia Universidad Javeriana -Instituto Pensar. 
Foucault, M. (2004). La hermenéutica del sujeto. Fondo de Cultura Económica.

Foucault, M. (2010). El coraje de la verdad: el gobierno de sí y de los otros II. Fondo de Cultura Económica.

Foucault, M. (2014). El gobierno de sí y de los otros. Fondo de Cultura Económica.

Gómez, N. (2001). Escolios a un texto implícito. Selección. Villegas Editores.

Gómez, N. (2010). Textos. Ediciones Atalanta.

Haraway, D. (1991). Ciencia, ciborgs y mujeres. La reinvención de la naturaleza. Ediciones Cátedra.

Hernández, E. (2013). Mediaciones en el conflicto armado colombiano. Hallazgos desde la investigación para la paz. CONfines de Relaciones Internacionales y Ciencia Politica, 9(18), 31-75. http://www.scielo.org.mx/pdf/confines/ v9n18/v9n18a2.pdf

Lederach, J. P. (2016). La imaginación moral: el arte y el alma de la construcción de la paz. Semana Libros.

Mac-Ginty, R. (2014). Everyday peace: Bottom-up and local agency in conflict-affected societies. Security Dialogue, 45(6), 548-564. https://journals.sagepub.com/doi/abs/10.1177/0967010614550899

Maquiavelo, N. (2010). El príncipe. Ediciones Akal.

Mèlich, J.C. (2012). Filosofía de la finitud. Herder.

Mèlich, J.C. (2014). Lógica de la crueldad. Herder.

Muñoz, F. (Ed.). (2001). La paz imperfecta. Editorial Universidad de Granada.

Muñoz, F. (s. f.). La paz imperfecta. Instituto de la Paz y los Conflictos de la Universidad de Granada. https://www.ugr.es/ fmunoz/documentos/ pimunozespañol.pdf

Ricoeur, P. (2001). La metáfora viva. Editorial Trotta. 
Tovar, C. (2013). Desplazamiento forzado: potencia política de la acción psicosocial. En A. Castillejo (Ed.). Violencia, memoria y sociedad: Debates y agendas en la Colombia actual (pp. 391-408). Editorial Universidad Santo Tomás de Aquino.

Vasilachis, I. (2006). La investigación cualitativa. En I. Vasilachis (Coord.). Estrategias de investigación cualitativa (pp. 23-64). Gedisa Editorial.

Weber, M. (2012). La ética protestante y el espíritu del capitalismo. Fondo de Cultura Económica. 
